\title{
A INSERÇÃO DO AGLOMERADO METROPOLITANO DE CURITIBA NAS REDES GLOBAIS E SEUS IMPACTOS SOBRE O MERCADO DE TRABALHO LOCAL
}

\section{The insertion of the metropolitan agglomerate of Curitiba in the global nets and their impacts on the local work market}

\author{
Luis Lopes DINIZ FILHO' \\ Silvana CROOPE ${ }^{2}$
}

\begin{abstract}
RESUMO
Este estudo analisa o processo de inserção do aglomerado metropolitano de Curitiba nas redes globais considerando o período a partir da década de 90 , quando esse processo se intensifica. Parte do conceito de redes e analisa a reestruturação produtiva local, com foco no setor de serviços e na dinâmica do mercado de trabalho local. Nesse período, Curitiba consolida a integração da sua área urbana às de algumas cidades vizinhas em função de intensificação de seus relacionamentos, conferindo uma nova dimensão espacial, urbana e de serviços à metrópole. Curitiba sofreu alterações na configuração do seu mercado de trabalho do setor serviços (empresas e profissões), mas sem inserção direta intensa nas redes globais.
\end{abstract}

\section{Palavras-chave:}

Redes globais; mercado de trabalho; serviços; reorganização produtiva.

\begin{abstract}
This study analyses the insertion process of Curitiba's agglomerated metropolitan region on the global net considering the period since the nineties, when this process gets more intense. It begins with the network concept and analyse the local productive re-structuring, focusing on the service sector and on the dynamic of the local work market. During this period, Curitiba consolidates its urban area integration together to some of the neighbors cities because of its relationships intensification, giving it a new spatial dimension, urban and of services to the metropolis. Curitiba suffered configuration changes on its work market of service sector (companies and professions), but without intense direct insertion on Global Nets.
\end{abstract}

\section{Key-words:}

Global network's; work market; services; productive reorganization.

\footnotetext{
${ }^{1}$ Professor adjunto doutor do Departamento de Geografia da UFPR

${ }^{2}$ Mestre em Geografia pela UFPR
} 
Na década de 90, a região da Grande Curitiba passou por várias mudanças estruturais relacionadas às transformações mais gerais que vêm ocorrendo em âmbito mundial, sob os auspícios do que vem sendo intitulado como "processo de globalização", em suas muitas facetas. Algumas características e conseqüências desse processo, como fluxos mais intensos de comércio internacional, o avanço tecnológico nas telecomunicações e transportes (com reflexos sobre a agilidade e eficiência das empresas), a ampliação dos fluxos de capital internacional, as novas formas de produção, que integram os processos produtivos em escala internacional, e, por conseguinte, a demanda por profissionais capazes de responder a essa nova configuração econômica mundial, estabelecem novas e inusitadas conexões entre pontos distantes do espaço global. Diante de tamanha complexidade de relações e conexões, a abordagem espacial tem muito a ganhar com o emprego da metodologia baseada no conceito de redes, que foi adotada para essa investigação.

Pelo caráter recente dessas mudanças, a análise dos impactos trazidos pela inserção do aglomerado metropolitano de Curitiba nas redes globais sobre o seu mercado de trabalho representa um desafio considerável, especialmente levando-se em conta que é no setor de serviços que tais impactos ocorrem de forma mais intensa. Com efeito, o setor serviços carrega em si grande dificuldade no trato analítico, pois abrange um universo de atividades extremamente heterogêneo, no qual se percebe a existência de relacionamentos independentes ou dependentes de outras atividades e de outros setores da economia, conforme a atividade de serviço escolhida para análise. Neste estudo, é essencial pôr em foco os serviços que se relacionam mais diretamente com os processos ligados à globalização, ou seja, aqueles que, por seus encadeamentos diretos ou indiretos com indústrias globalizadas, ou ainda por suas funções de coordenação e gestão de outras atividades econômicas e do próprio espaço, determinam as funções de cada aglomeração urbana nas redes globais.

Sendo assim, os objetivos gerais deste estudo são dois: analisar o grau de inserção do aglomerado metropolitano de Curitiba nas redes globais (a qual ocorreu de forma mais intensa a partir da década de 90) e avaliar o impacto que essa maior inserção internacional provocou no mercado de trabalho dessa região no período citado.

\section{CONSOLIDAÇÃO E REORGANIZAÇÃO PRODUTIVA DO AGLOMERADO METROPOLITANO}

O conceito de rede, inicialmente associado à idéia de serviço gerido por grandes empresas, hoje diz respeito, de forma mais usual, às atividades de coordenação e transação entre economia de mercado e estado, e que operam como fator de coesão entre lugares. Trata-se, pois, de um conceito que visa identificar e analisar as atividades que operam como transgressoras de territórios, já que não se limitam às fronteiras administrativas, ou ainda como articuladoras de "pontos" do espaço em diversas escalas, desde a local até a global (DIAS; 2003, p. 89-92). Essa abordagem metodológica considera a distinção entre redes urbanas e redes globais, cabendo pois analisar o posicionamento de Curitiba em relação a esses dois tipos de redes, em âmbito nacional e internacional. $^{3}$

As relações econômicas e sociais que se estruturam sob a forma de redes extrapolam os limites administrativos dos municípios, conformando espaços metropolitanos que se conectam a outras cidades nacionais e internacionais. A Região Metropolitana de Curitiba - RMC foi estabelecida nos anos 70 por meio de lei federal, ${ }^{4} \mathrm{e}$, após vários desmembramentos e incorporações de municípios, veio a abranger um conjunto de 25 municípios, nos dias de hoje. Todavia, como bem observa Firkowski (2001, p. 15):

\begin{abstract}
A despeito da constituição oficial da Região Metropolitana de Curitiba ter se dado na década de 70 , o processo de metropolização assume significado real apenas na década de 90 , quando parcelas significativas das atividades econômicas - principalmente a fabril - e da população passam a se distribuir pelos municípios componentes do aglomerado metropolitano, aproximadamente doze municípios, em contraposição aos vinte e cinco que fazem parte da Região Metropolitana [...]. ${ }^{5}$
\end{abstract}

${ }^{3}$ Uma discussão mais detalhada sobre o conceito de rede e a distinção entre redes urbanas e globais pode ser encontrada em (CROOPE, 2005, p. 15-25)

${ }^{4} \mathrm{O}$ processo de institucionalização das regiões metropolitanas brasileiras ocorreu em duas fases: a primeira nos anos 70 - Lei Complementar $n .^{\circ}$ 14/73, como parte da política nacional de desenvolvimento urbano, na qual foi instituída a RMC; a segunda com a Constituição Federal de 1988, que deixava como atribuição dos estados federados a competência de institucionalização de suas unidades regionais. Em 2003, o Brasil contava com 26 unidades metropolitanas oficialmente instituídas, entre elas a de Curitiba (MOURA et al., 2005).

${ }^{5}$ Segundo a autora, são eles, além de Curitiba: Almirante Tamandaré, Araucária, Campina Grande do Sul, Campo Largo, Campo Magro, Colombo, Fazenda Rio Grande, Pinhais, Piraquara, Quatro Barras e São José dos Pinhais. 
DINIZ FILHO, L.L.; CROOPE, S. A inserção do aglomerado...

FIGURA 1 - MAPA DA REGIÃO METROPOLITANA DE CURITIBA - ÁREA CONURBADA

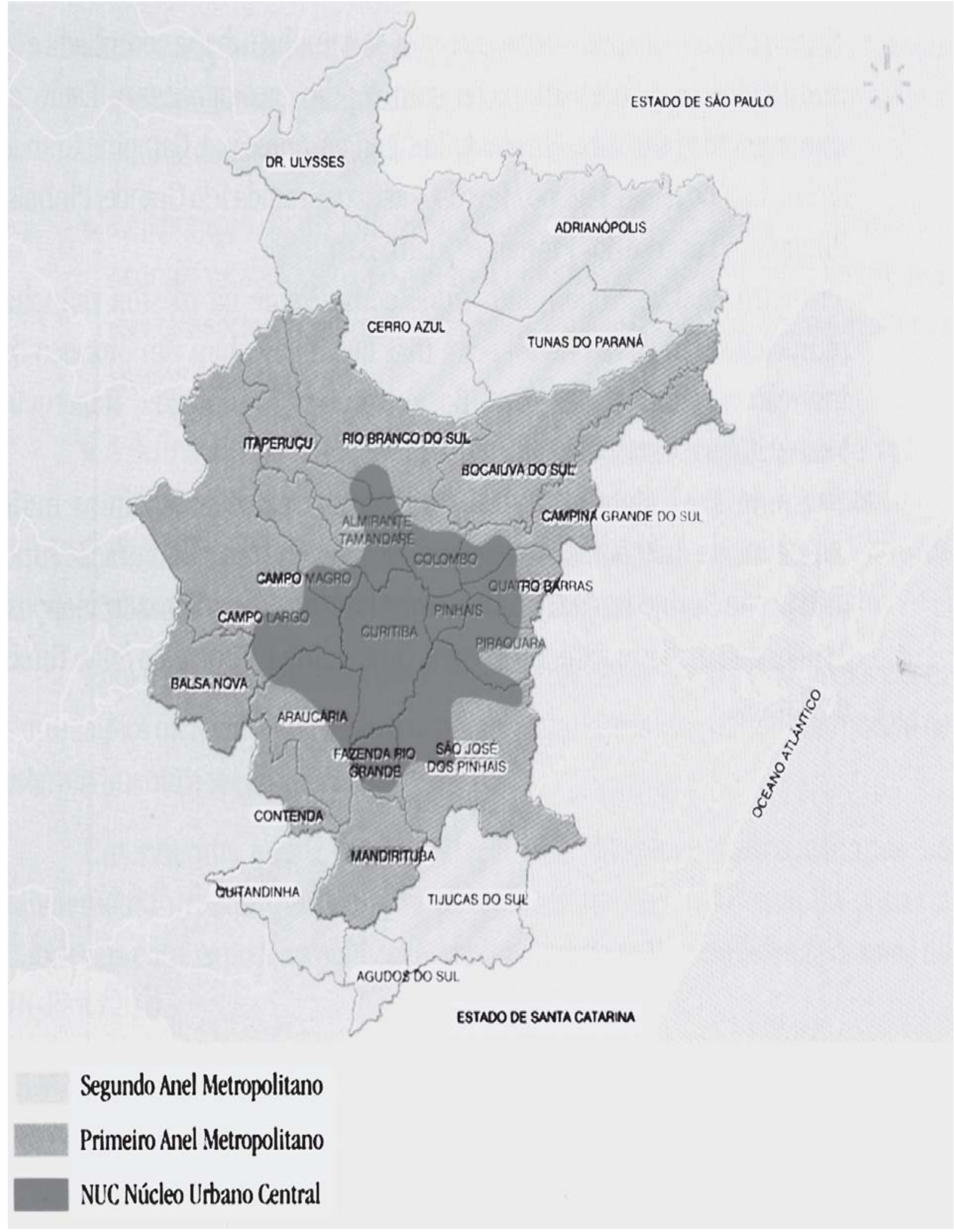

FONTE: COMEC 
De fato, o artificialismo da Região Metropolitana legalmente estabelecida já é reconhecido pelo próprio poder público. A COMEC - Coordenação da Região Metropolitana de Curitiba, ao elaborar o mais recente Plano de Desenvolvimento Integrado para a RMC, com vistas a ampliar a competitividade dessa região e sua inserção na economia global, efetuou uma divisão sub-regional que compreende três categorias espaciais (Figura 1): a) núcleo urbano central - malha urbana conurbada e municípios com forte interação com o pólo metropolitano, composto por Curitiba e as cidades que Ihe fazem fronteira direta (12 cidades); b) primeiro anel metropolitano - composto por municípios limítrofes ao pólo e que apresentam inserção regional (6 cidades) e; c) segundo anel metropolitano composto pelos municípios mais recentemente incorporados à região, nos quais predominam o espaço rural $\mathrm{e}$ onde a urbanização é incipiente (7 cidades). ${ }^{6}$

A importância dos anos 90 na consolidação do aglomerado metropolitano é bastante clara, segundo dados utilizados na elaboração desse plano: em 1991, Curitiba era responsável por $64 \%$ da ocupação urbana total no espaço metropolitano e os municípios limítrofes (primeiro anel) eram responsáveis por $25 \%$; em 2000 , Curitiba corresponde a $58 \%$ e os municípios limítrofes a $32 \%{ }^{7}$

O período entre 1996 e 2000, segundo dados do IBGE, apresentou as seguintes taxas médias anuais de crescimento demográfico: Curitiba 1,82\%, Piraquara $8,53 \%$, Fazenda Rio Grande 8,34\%, Rio Branco do Sul 6,01\%; Campo Magro 5,57\%; Araucária 5,26\%; São José dos Pinhais 4,84\%; Almirante Tamandaré 4,82\%; Colombo $4,51 \%$, e demais menos representativas.

O crescimento dos municípios da RMC, excluindo-se Curitiba, foi de $2,9 \%$, o que revela uma taxa bem superior ao crescimento da capital considerada isoladamente. A taxa de crescimento do Paraná no mesmo período foi de $1,5 \%$, o que demonstra o ritmo mais acelerado do crescimento demográfico da RMC sem Curitiba. Conforme Motta (IPEA, 2000, p. 69-70), esse extravasamento da população do pólo para áreas vizinhas constitui um típico processo de periferização, com alta densidade e elevado grau de urbanização. Assim, a RMC contava com 2.000.805 habitantes no ano de 1991, e em 2000 já contava com 2.812.050 habitantes, segundo o IBGE, tendo centralidade de nível máximo, abran- gendo todos os municípios do Paraná e grande parte dos de Santa Catarina.

As tendências demográficas apontam fortalecimento da RMC dentro da rede urbana brasileira nos próximos anos, segundo documento da Curitiba S.A. (2001), 8 "Mercado de Trabalho em Curitiba e Região Metropolitana (versão preliminar)", que afirma que "a Região Metropolitana de Curitiba é uma das regiões metropolitanas que apresentam as maiores taxas de crescimento populacional do Brasil, cuja região tornou-se foco de forte atração populacional, devendo corresponder a aproximadamente 3,7 milhões de pessoas no ano 2010 ". Ou seja, está se "tornando um pólo concentrador de população, com a característica de um fenômeno denominado metropolização periférica, onde o município núcleo - Curitiba - expulsa população para os municípios circunvizinhos e muitos desses apresentam taxas de crescimento populacional maior do que a do núcleo metropolitano". ${ }^{9}$

Outro fator responsável pelo processo de metropolização é o crescimento industrial, com sua progressiva dispersão espacial dentro do aglomerado metropolitano, que teve início ainda nos anos 70 , embora de forma pouco expressiva em comparação com o período recente. De acordo com Lunardi (1997), na década de 90, como resultado de um processo contínuo de planejamento urbano, que teve início nos anos 60, a RMC despontou como espaço privilegiado para a instalação de novos empreendimentos no contexto da desconcentração da indústria brasileira, em virtude da sua infra-estrutura urbana e dos bons níveis de qualidade de vida que a cidade oferece.

Com efeito, nas fases de modernização acelerada da estrutura produtiva brasileira, como foi o caso dos anos 90 , algumas áreas tendem a crescer com maior rapidez por serem dotadas de fatores de produção mais sofisticados, que funcionam como atrativos para os investimentos nas indústrias mais intensivas em capital, mormente nos segmentos de bens de produção e de duráveis de consumo. Essa forma de desconcentração industrial acompanha a expansão e adensamento progressivos da rede urbana, já que esses fatores de produção estão intimamente associados à urbanização, sendo eles: a) a oferta de infra-estruturas de transporte, energia, telecomunicações e, no caso de indústrias de alta tecnologia,

\footnotetext{
${ }^{6}$ Trabalho desenvolvido ao longo de anos, apresentado em "Documento síntese" (2001), e editado em "Metrópolis em Revista, Planejamento Regional" da COMEC/ Governo do Paraná (2002, v. 4).

${ }^{7}$ Esse processo resulta de uma inversão de tendências ocorrido a partir de 1996, visto que, segundo Motta (IPEA, 2000, p. 55-57), desde 1970 até essa data, a taxa de crescimento demográfico da cidade de Curitiba foi maior que a taxa estadual.

${ }^{8}$ Companhia de Desenvolvimento da Curitiba Metrópole - CDC é a denominação que passou a ser atribuída à antiga Cidade Industrial de Curitiba - CIC a partir de 03 jan. 2005; mais recentemente, essa instituição passou a ser identificada como Curitiba S.A.

${ }^{9}$ Não é por acaso, pois, que a RMC apresenta um percentual maior de pessoas nas faixas etárias mais jovens, entre 15 e 34 anos; esse perfil é típico de cidades que recebem grandes contingentes migratórios, segundo o mesmo documento citado.
} 
também da infra-estrutura de pesquisa científica e tecnológica - universidades e centros de pesquisa; b) a oferta de serviços de apoio à produção mais sofisticados (marketing, pesquisa de mercado, consultorias de variados tipos, etc.), própria dos grandes centros metropolitanos; c) estrutura industrial razoavelmente diversificada, que favoreça o estabelecimento de nexos produtivos para frente e para trás; d) mercados consumidores mais diversificados e exigentes; e) oferta de mão-de-obra qualificada; f) boa qualidade de vida, o que inclui uma oferta satisfatória de serviços de lazer e de bens culturais (DINIZ FILHO, 2000).

Assim, a desconcentração industrial brasileira dos anos 90 , que beneficiou principalmente as cidades médias do interior paulista e as metrópoles dos estados vizinhos a São Paulo, notadamente as do sul, foi bastante intenso no segmento automobilístico, e esteve associado à formação do Mercosul - destino de grande parte de produção. Nessa década, acontece a entrada de importantes capitais industriais no Brasil, posto que as condições econômicas internas melhoraram, houve maior estabilização da moeda e, desse modo, as ações de atração de capitais praticadas por governos estaduais e locais produziram grandes alterações na industrialização e metropolização de Curitiba (FIRKOWSKI, 2001, p. 21-22).

À oferta de fatores de produção sofisticados no aglomerado metropolitano de Curitiba somaram-se ainda as ações implementadas pelo governo estadual para atrair investimentos industriais, expressas numa agressiva política de incentivos fiscais, ${ }^{10}$ que estimulou a instalação de fábricas em outros municípios metropolitanos que não Curitiba. ${ }^{11}$ Com efeito, o esforço governamental encetado para reposicionar Curitiba na matriz industrial brasileira, materializado principalmente no programa Paraná Mais Empregos, levou 67 indústrias a assinar o protocolo de intenções com o governo do estado para aderir a esse programa e usufruir dos benefícios relacionados ao recolhimento do ICMS. A partir de $1995,81 \%$ das empresas optaram por localizar-se nas cidades do aglomerado que não Curitiba, o que correspondeu a $82 \%$ dos capi- tais investidos no estado e $70 \%$ dos empregos gerados. São José dos Pinhais sozinha recebeu $36 \%$ das novas indústrias, $61 \%$ dos capitais e $43 \%$ dos empregos. Já em Curitiba, a metade dos investimentos realizados destinava-se à ampliação ou reconversão de estabelecimentos já existentes, o que não permite a inclusão desses investimentos nas estatísticas citadas de investimento.

Houve portanto uma mudança qualitativa na estrutura industrial da RMC, posto que os maiores ganhos recentes no valor adicionado da indústria de transformação regional ocorreram na indústria metal-mecânica: de uma participação de $12,59 \%$ no triênio $1980-82$, esta passou a representar $21,45 \%$ no triênio $1994-96$, resultado da maturação de investimentos da década de 90 (FIRKOWSKI; 2001). Dentro desse universo, houve predomínio da indústria de materiais de transportes no total dos investimentos realizados na segunda metade dos anos 90 , sob a égide do programa Paraná Mais Empregos, já que essa indústria foi responsável por $50 \%$ das implantações, mesmo sem contar as que produzem componentes para a produção de veículos.

Assim, a RMC, que até 1998 contava com algumas indústrias de produção de ônibus, caminhões e máquinas agrícolas instaladas no início dos anos 70 , tais como Volvo e New Holland, passou a ter indústrias de produção de veículos leves. Tais indústrias trouxeram um novo padrão tecnológico, em termos de automação, métodos organizacionais, produção baseada no sistema just in time, demanda de mão-de-obra qualificada e flexível, ou seja, uma reestruturação produtiva e organizacional. No aglomerado metropolitano, houve a implantação de importantes indústrias transnacionais, como a Renault e a Audi/Volkswagen (São José dos Pinhais), com conseqüente concentração de fornecedores nas áreas ao redor das montadoras e aumento da demanda de mais ou mesmo novas modalidades de serviços. Esses novos espaços foram acompanhados por ocupações irregulares efetuadas por pessoas de baixa renda, bem como também a formação de condomínios de classe média e alta com regularização dessas áreas nobres. ${ }^{12}$

${ }^{10}$ Ao verificar o enorme contraste entre o atual dinamismo industrial da RMC (bem como a localização de novas plantas em áreas de proteção de mananciais) e o que era previsto nos planos de desenvolvimento elaborados recentemente, que valorizavam muito a sustentabilidade ambiental e a preservação dos mananciais, Firkowski (2001, p. 5) conclui: "[...] percebe-se que em algum momento dos últimos vinte anos, os rumos pretendidos foram subvertidos, revelando a produção de um "outro" espaço muito diferente daquele outrora idealizado. Com isso evidencia-se a existência de importantes forças modificadoras da realidade, forças essas de origem econômica, social e política, que não podem ser aprisionadas e tampouco compreendidas senão no próprio contexto de sua ação transformadora e da produção espacial que engendram".

${ }^{11}$ Especificamente no município de Curitiba, cabe mencionar a constituição de um pólo de produção de software visando exportação, através de um programa do governo municipal, sendo esta uma tentativa de transformar a cidade num tecnopolo, de modo a redimensionála num novo patamar do processo de reprodução capitalista atual, além de servir como reforço à imagem de modernidade e inovação, costumeiramente associadas a Curitiba (FIRKOWSKI; 2001, p. 5-6)

${ }^{12} \mathrm{O}$ município de Campo Largo assistiu no período à implantação da indústria da Chrysler, e depois o fechamento da mesma, criando a necessidade de administração do prejuízo social e financeiro (fiscal) desse fechamento. 
A reestruturação produtiva se expressa espacialmente na formação do espaço metropolitano, através de crescente incorporação de novas áreas à dinâmica metropolitana, que não se limitam às sedes político-administrativas da cidade central. A realidade metropolitana de Curitiba acaba por modificar o padrão de localização das atividades industriais e de serviços, bem como de pessoas, dentro de seu espaço.

Esses investimentos industriais estimularam a instalação de atividades com maior grau de especialização em Curitiba, como as grandes redes varejistas (hipermercados e shopping centers) e do setor hoteleiro (redes da hotelaria mundial). Ocorreu também a valorização do solo em Curitiba e a modificação dos espaços urbanos residenciais, com conseqüente expulsão das camadas mais pobres da população para a periferia da metrópole (como as áreas de mananciais de Pinhais e Piraquara) e aumento de migrantes de baixa renda atraídos pelas supostas possibilidades de emprego. Em contraste, a expansão dos estratos de trabalhadores mais qualificados, exigi- dos pelas novas atividades industriais e de serviços mais sofisticados, passou a gerar aumento da demanda por novos condomínios residenciais de padrão mais elevado, como o Alphaville Graciosa. Como afirma Firkowski (2001):

O novo conteúdo urbano de Curitiba, que tem no aglomerado metropolitano sua forma espacial, surge da relação entre a desconcentração e a nova dinâmica industrial e expressa-se pela recomposição funcional de Curitiba, que passa a ter novas funções, capazes de transformá-la, de fato, em metrópole, bem como inseri-la no amplo espaço de relações globais que se intensificam.

Nesse sentido, a nova forma de organização da indústria, produzindo espaços diferenciados através da recriação e requalificação de espaços anteriormente existentes, é um fenômeno que pode ser observado também nos serviços, gerando mudanças no mercado de trabalho de Curitiba associadas à emergência da metropolização e à conformação da rede de cidades globais.

TABELA 1 - ESTABELECIMENTOS DE SERVIÇOS EM CURITIBA - 1996/2002

\begin{tabular}{|c|c|c|c|c|c|c|c|c|}
\hline \multicolumn{9}{|c|}{ EVOLUÇÃO DOS ESTABELECIMENTOS DE SERVIÇOS EM CURITIBA - 1996-2002 } \\
\hline & & & & & & & & $\%$ de Var. \\
\hline DESCRIÇÃO DA ATIVIDADE & 1996 & 1997 & 1998 & 1999 & 2000 & 2001 & 2002 & 96 a 02 \\
\hline Alojamento e alimentação & 4.725 & 5.150 & 5.381 & 5.725 & 5.987 & 6.449 & 6.508 & 37,74 \\
\hline Transporte terrestre & 1.252 & 1.465 & 1.539 & 1.690 & 1.899 & 2.083 & 2.134 & 70,45 \\
\hline Transporte aquaviário & 3 & 3 & 3 & 6 & 6 & 5 & 3 & 0,00 \\
\hline Transporte aéreo & 34 & 33 & 37 & 25 & 34 & 27 & 24 & $-29,41$ \\
\hline $\begin{array}{l}\text { Atividades anexas e auxiliares do transporte e } \\
\text { Agências de viagem }\end{array}$ & 566 & 636 & 761 & 898 & 1.073 & 1.182 & 1.255 & 121,73 \\
\hline Correio e telecomunicações & 148 & 174 & 183 & 252 & 272 & 310 & 350 & 136,49 \\
\hline Intermediação financeira & 1.915 & 615 & 635 & 639 & 693 & 801 & 820 & $-57,18$ \\
\hline Seguros e previdência complementar & 344 & 340 & 298 & 317 & 315 & 321 & 297 & $-13,66$ \\
\hline $\begin{array}{l}\text { Atividades auxiliares da intermediação financeira, } \\
\text { Seguros e prev.complementar }\end{array}$ & 568 & 532 & 575 & 677 & 790 & 928 & 967 & 70,25 \\
\hline Atividades imobiliárias & 3.706 & 3.923 & 4.280 & 4.571 & 5.192 & 5.498 & 5.683 & 53,35 \\
\hline $\begin{array}{l}\text { Aluguel de veículos, máquinas e equipamentos } \\
\text { Sem condutores ou op..... }\end{array}$ & 364 & 429 & 486 & 539 & 663 & 807 & 909 & 149,73 \\
\hline Atividades de informática e serviços relacionados & 1.339 & 1.447 & 1.545 & 1.646 & 1.836 & 2.051 & 2.186 & 63,26 \\
\hline Pesquisa e desenvolvimento & 28 & 22 & 28 & 36 & 43 & 56 & 56 & 100,00 \\
\hline $\begin{array}{l}\text { Serviços prestados principalmente as empresas } \\
\text { Administração pública, defesa e seguridade }\end{array}$ & 8.319 & 9.416 & 10.223 & 11.398 & 12.422 & 13.438 & 13.795 & 65,83 \\
\hline social & 210 & 213 & 215 & 221 & 228 & 176 & 163 & $-22,38$ \\
\hline Educação & 980 & 1.086 & 1.175 & 1.264 & 1.357 & 1.469 & 1.407 & 43,57 \\
\hline Saúde e serviços sociais & 2.566 & 2.924 & 3.284 & 3.576 & 3.996 & 4.327 & 4.527 & 76,42 \\
\hline Limpeza urbana e esgoto e atividades & & & & & & & & \\
\hline relacionadas & 0 & 0 & 22 & 0 & 0 & 0 & 0 & 0,00 \\
\hline Atividades associativas & 1.985 & 2.307 & 2.874 & 3.192 & 3.415 & 3.731 & 4.018 & 102,42 \\
\hline Atividades recreativas, culturais e desportivas & 1.106 & 1.123 & 1.229 & 1.250 & 1.354 & 1.479 & 1.593 & 44,03 \\
\hline Serviços pessoais & 1.177 & 1.316 & 1.385 & 1.513 & 1.495 & 1.540 & 1.606 & 36,45 \\
\hline Serviços domésticos & 30 & 22 & 15 & 26 & 61 & 106 & 110 & 266,67 \\
\hline $\begin{array}{l}\text { Organismos internacionais e outras instituições } \\
\text { Extraterritoriais }\end{array}$ & 8 & 8 & 4 & 0 & 0 & 8 & 14 & 75,00 \\
\hline Outros & 50 & 44 & 3.849 & 67 & 60 & 67 & 81 & 62,00 \\
\hline TOTAL & 31.423 & 33.228 & 40.026 & 39.528 & 43.191 & 46.859 & 48.506 & 54,36 \\
\hline TOTAL DE CURITIBA & 91.235 & 84.970 & 83.049 & 89.267 & 95.296 & 101.939 & 104.496 & 14,53 \\
\hline
\end{tabular}

FONTE: MTE / DES / CGET/RAIS_1996 A 2002

ELABORAÇÃO: CIC/ASSESSORIA DE PLANEJAMENTO E INFORMAÇÕES 


\section{A TRAJETÓRIA RECENTE DO SETOR SERVIÇOS NO CONTEXTO METROPOLITANO: IMPACTOS SOBRE O MERCADO DE TRABALHO}

Sob o efeito da reestruturação produtiva, observouse em Curitiba, no período 1994 - 1998, uma redução dos postos de trabalho na indústria de transformação, acompanhada de grande aumento de postos no setor de serviços, que compensou, até certo ponto, a perda de postos industriais, fenômeno esse que também ocorreu em outras regiões metropolitanas no mesmo período (Salvador, Recife, Belo Horizonte, São Paulo e Porto Alegre), e que é denominado de compensação inter-setorial. ${ }^{13}$

O tipo de expansão ocorrida no setor serviços de Curitiba, no que se refere ao perfil dos postos de trabalho criados nesse setor no âmbito da metrópole, apresenta algumas peculiaridades. Os dados mais recentes sobre o setor serviços em Curitiba, cedidos pela CDC (2004), com informações retiradas da base RAIS do Ministério do Trabalho e Emprego, apresenta números relativos às empresas que declaram a RAIS para o ministério, ${ }^{14}$ conforme a Tabela 1.

Como pode ser observado na tabela 1 , os tipos de serviços que costumam estar mais evidentes nas cidades globais, como serviços prestados a empresas, atividades imobiliárias e telecomunicações (SASSEN; 1998), correspondem também àqueles que vêm tendo crescimento mais acelerado em Curitiba.

Os dados referentes à dinâmica do emprego mostram essa mesma trajetória verificada pelo número de estabelecimentos do setor, conforme a tabela abaixo. Embora os dados da tabela não permitam fazer distinções quanto ao nível de qualificação exigido dentro de cada categoria de empregos listada, o que seria impor-

TABELA 2 - EMPREGOS NO SETOR SERVIÇOS - CURITIBA - 1996/2002

\begin{tabular}{|c|c|c|c|c|c|c|c|c|}
\hline \multicolumn{9}{|c|}{ EMPREGOS NO SETOR DE SERVIÇOS, EM CURITIBA - 1996-2002 } \\
\hline DESCRIÇÃO DA ATIVIDADE & 1996 & 1997 & 1998 & 1999 & 2000 & 2001 & 2002 & $\begin{array}{l}\% \text { de Var. } \\
96 \text { a } 02\end{array}$ \\
\hline Alojamento e alimentação & 14.570 & 16.058 & 16.097 & 16.718 & 18.261 & 18.668 & 19.242 & 32,07 \\
\hline Transporte terrestre & 26.324 & 28.080 & 23.486 & 21.147 & 23.101 & 22.371 & 22.237 & $-15,53$ \\
\hline Transporte aquaviário & 10 & 3 & 3 & 5 & 12 & 15 & 2 & $-80,00$ \\
\hline Transporte aéreo & 397 & 429 & 465 & 348 & 268 & 266 & 303 & $-23,68$ \\
\hline $\begin{array}{l}\text { Atividades anexas e auxiliares do transporte e } \\
\text { Agencias de viagem }\end{array}$ & 2.234 & 1.928 & 2.652 & 2.854 & 3.261 & 4.041 & 3.532 & 58,10 \\
\hline Correio e telecomunicações & 8.742 & 8.773 & 13.574 & 10.138 & 9.403 & 8.598 & 5.541 & $-36,62$ \\
\hline Intermediação financeira & 21.430 & 21.236 & 15.789 & 12.194 & 13.114 & 13.994 & 14.428 & $-32,67$ \\
\hline Seguros e previdência complementar & 4.058 & 1.928 & 1.655 & 1.625 & 1.808 & 2.028 & 2.189 & $-46,06$ \\
\hline $\begin{array}{l}\text { Atividades auxiliares da intermediação financeira, } \\
\text { Seguros e prev.complementar }\end{array}$ & 1.556 & 1.916 & 2.045 & 1.710 & 1.743 & 1.091 & 1.084 & $-30,33$ \\
\hline Atividades imobiliárias & 11.417 & 11.875 & 12.373 & 13.047 & 14.327 & 15.084 & 15.092 & 32,19 \\
\hline $\begin{array}{l}\text { Aluguel de veículos, maquinas e equipamentos } \\
\text { Sem condutores ou op..... }\end{array}$ & 1.399 & 1.474 & 1.705 & 792 & 1.648 & 1.863 & 1.872 & 33,81 \\
\hline Atividades de informática e serviços relacionados & 4.574 & 5.217 & 4.735 & 4.864 & 5.265 & 5.019 & 4.627 & 1,16 \\
\hline Pesquisa e desenvolvimento & 435 & 408 & 417 & 521 & 656 & 465 & 788 & 81,15 \\
\hline Serviços prestados principalmente as empresas & 36.834 & 43.450 & 43.594 & 46.036 & 49.858 & 53.263 & 54.774 & 48,71 \\
\hline ção publica, defesa e sec & 153.887 & 165.001 & 166.066 & 156.879 & 160.792 & 146.369 & 143.587 & $-6,69$ \\
\hline Educação & 17.095 & 17.250 & 18.899 & 19.842 & 20.636 & 21.118 & 21.169 & 23,83 \\
\hline Saúde e serviços sociais & 18.207 & 22.062 & 22.306 & 24.408 & 25.070 & 24.891 & 27.449 & 50,76 \\
\hline Limpeza urbana e esgoto e atividades & & & & & & & & \\
\hline relacionadas & 0 & 0 & 1.940 & 0 & 0 & 0 & 0 & 0,00 \\
\hline Atividades as & 11.179 & 14.673 & 13.970 & 13.566 & 13.955 & 26.953 & 34.312 & 206,93 \\
\hline Atividades recreativas, culturais e desportivas & 6.988 & 7.157 & 6.227 & 6.923 & 6.801 & 6.552 & 6.585 & $-5,77$ \\
\hline Serviço & 1.651 & 2.036 & 2.557 & 2.561 & 2.358 & 2.628 & 2.628 & 59,18 \\
\hline Serviços domésticos & 37 & 25 & 14 & 20 & 58 & 74 & 194 & 424,32 \\
\hline $\begin{array}{l}\text { Organismos internacionais e outras instituições } \\
\text { Extraterritoriais }\end{array}$ & 14 & 13 & 7 & 0 & 0 & 44 & 16 & 14,29 \\
\hline Outros & 531 & 398 & 310 & 259 & 206 & 212 & 158 & $-70,24$ \\
\hline TOTAL & 343.569 & 371.390 & 370.886 & 356.457 & 372.601 & 375.607 & 381.809 & 11,13 \\
\hline TOTAL DE CURITIBA & 535.911 & 573.183 & 560.563 & 541.965 & 568.581 & 572.772 & 585.972 & 9,34 \\
\hline
\end{tabular}

FONTE: MTE / DES / CGET/ RAIS_1996 A 2002

ELABORAÇÃO: CIC/ASSESSORIA DE PLANEJAMENTO E INFORMAÇÕES

${ }^{13}$ Essa avaliação foi realizada com base nas informações fornecidas pelo Conselho Municipal do Trabalho de Curitiba originalmente apresentadas na obra "Caracterização Geral do Mercado de Trabalho da Região Metropolitana de Curitiba e de seus Municípios Circunvizinhos" (CIC, 2001).

${ }^{14}$ Há, nesse sentido, uma porcentagem não incluída de empresas que não têm por obrigatoriedade declarar a RAIS. Segundo informado pela CDC, contudo, esse grupo representa uma porcentagem mínima do total. 
DINIZ FILHO, L.L.; CROOPE, S. A inserção do aglomerado...

tante para aquilatar a expansão das empresas de serviços modernas, que são decisivas do ponto de vista da inserção da metrópole nas redes urbanas e globais, a série sugere que o movimento de transformação na estrutura produtiva de Curitiba reforça a posição dessa cidade como núcleo de um espaço metropolitano em consolidação e crescentemente internacionalizado, já que o comportamento do mercado de trabalho local é similar ao que se observa nas cidades globais, onde há desta- que para atividades do setor serviços, principalmente serviços prestados a empresas, segundo defendido por Sassen (1998), IBGE (1995) e IPEA (1998).

Quanto ao peso relativo de Curitiba no conjunto da RMC, bem como na economia estadual e nacional, cabe examinar os dados fornecidos pela CDC (2004), conforme a tabela abaixo. ${ }^{15}$

Essas estatísticas a respeito de Curitiba indicam ter havido um decréscimo de participação populacional,

TABELA 3 - PARTICIPAÇÃO DOS EMPREGOS DE CURITIBA NA REGIÃO METROPOLITANA, NO PARANÁ E NO BRASIL

PARTICIPAÇÃO DOS EMPREGOS DE CURITIBA NA RMC, PARANÁ E BRASIL 1996 A 2002

\begin{tabular}{l|r|r|r|r|r|r|r}
\hline PARTICIPAÇÃO & 1996 & 1997 & 1998 & 1999 & $\mathbf{2 0 0 0}$ & $\mathbf{2 0 0 1}$ & $\mathbf{2 0 0 2}$ \\
\hline \% DE CURITIBA NA RMC & 82,32 & 82,00 & 80,54 & 78,45 & 78,35 & 77,38 & 76,13 \\
\hline \% DE CURITIBA NO PARANÁ & 37,09 & 37,45 & 35,93 & 34,28 & 34,39 & 33,27 & 32,33 \\
\hline \% DE CURITIBA NO BRASIL & 2,25 & 2,38 & 2,29 & 2,17 & 2,17 & 2,11 & 2,04 \\
\hline
\end{tabular}

FONTE: MTE / DES / CGET/RAIS_1996 a 2002

ELABORAÇÃO: CIC/Assessoria de Planejamento e Informações

PARTICIPAÇÃO DOS EMPREGOS DE CURITIBA NO SETOR INDUSTRIAL NA RMC, PARANÁ E BRASIL - 1996 A 2002

\begin{tabular}{|c|c|c|c|c|c|c|c|}
\hline PARTICIPAÇÃO & 1996 & 1997 & 1998 & 1999 & 2000 & 2001 & 2002 \\
\hline$\%$ DE CURITIBA NA RMC & 64,51 & 64,25 & 62,26 & 59,66 & 58,20 & 58,59 & 56,07 \\
\hline \% DE CURITIBA NO PARANÁ & 25,18 & 24,96 & 23,51 & 22,25 & 21,86 & 21,12 & 19,53 \\
\hline$\%$ DE CURITIBA NO BRASIL & 1,55 & 1,68 & 1,62 & 1,56 & 1,55 & 1,54 & 1,49 \\
\hline
\end{tabular}

PARTICIPAÇÃO DOS EMPREGOS DE CURITIBA NO SETOR COMERCIAL NA RMC, PARANÁ E BRASIL - 1996 A 2002

\begin{tabular}{l|r|r|r|r|r|r|r}
\hline PARTICIPAÇÃO & $\mathbf{1 9 9 6}$ & $\mathbf{1 9 9 7}$ & $\mathbf{1 9 9 8}$ & $\mathbf{1 9 9 9}$ & $\mathbf{2 0 0 0}$ & $\mathbf{2 0 0 1}$ & $\mathbf{2 0 0 2}$ \\
\hline \% DE CURITIBA NA RMC & 82,74 & 82,23 & 80,39 & 79,44 & 80,04 & 78,46 & 78,00 \\
\hline & & & & & & & \\
\hline \% DE CURITIBA NO PARANÁ & 32,44 & 31,81 & 31,06 & 30,36 & 30,41 & 28,98 & 28,77 \\
\hline \% DE CURITIBA NO BRASIL & 2,17 & 2,17 & 2,14 & 2,11 & 2,07 & 1,99 & 2,01 \\
\hline
\end{tabular}

FONTE: MTE / DES / CGET/ RAIS_1996 a 2002

ELABORAÇÃO: CIC/Assessoria de Planejamento e Informações

PARTICIPAÇÃO DOS EMPREGOS DE CURITIBA NO SETOR DE SERVIÇOS NA RMC, PARANÁ E BRASIL - 1996 A 2002

\begin{tabular}{l|r|r|r|r|r|r|r}
\hline PARTICIPAÇÃO & 1996 & 1997 & 1998 & 1999 & $\mathbf{2 0 0 0}$ & $\mathbf{2 0 0 1}$ & $\mathbf{2 0 0 2}$ \\
\hline \% DE CURITIBA NA RMC & 88,23 & 88,46 & 86,93 & 85,00 & 84,92 & 83,77 & 82,89 \\
\hline \% DE CURITIBA NO PARANÁ & 46,54 & 47,81 & 46,46 & 44,27 & 44,43 & 43,07 & 42,25 \\
\hline \% DE CURITIBA NO BRASIL & 2,67 & 2,83 & 2,71 & 2,55 & 2,57 & 2,49 & 2,39 \\
\hline
\end{tabular}

FONTE: MTE / DES / CGET/ RAIS_1996 a 2002

ELABORAÇÃO: CIC/Assessoria de Planejamento e Informações

${ }^{15}$ Vale observar que as séries desagregam o setor comércio das estatísticas de serviço em função dos critérios que são utilizados na coleta e organização dos dados, como se nota, por exemplo, no que diz respeito à legislação tributária; as vendas do comércio são tributadas pelo ICMS (imposto sobre circulação de mercadorias e serviços), enquanto o setor serviços é tributado pelo ISS (imposto sobre serviços). 
apesar de o comportamento da cidade quanto à trajetória do setor serviços se assemelhar ao das cidades globais. Isto deriva da extrapolação dos limites geográficos da cidade núcleo da metrópole pelos fluxos de pessoas, mercadorias e informações, sendo importante lembrar que as cidades globais não estão inscritas dentro de seus limites político-administrativos. Elas contam com um espaço de relações mais amplo, estabelecido dentro de áreas conurbadas, compostas por áreas das cidades vizinhas que participam intensamente nos fluxos. Essas áreas conurbadas e dinâmicas normalmente podem ser identificadas como parcela de uma metrópole, mesmo que a metrópole não possa ser identificada como global. Isso acaba por permitir uma avaliação sob dois enfoques paralelos: o de rede global e o de rede urbana, cada qual com seus elementos de análise bem determinados serviços urbanos ou redes de empresas.

Resgatando o passado, pode ser verificado que a cidade de Curitiba vinha contando e se orientando com uma visão de desenvolvimento. Ela foi uma das primeiras cidades brasileiras a contar com a instalação de uma universidade, um dos elementos considerados chave para o relacionamento com o resto do mundo e potencial para incrementar o desenvolvimento.

Mais recentemente, Curitiba buscou estar presente nos canais de mídia aparecendo com apelos (capital ecológica, capital social) para atrair os olhares das pessoas e alavancar mais relacionamentos, inserção e comercialização; em 2003 foi eleita capital americana da cultura (título este que divide com a cidade do Panamá), e seu sistema de transporte urbano tem sido alvo de estudos por especialistas internacionais. Então, considerando os três aspectos mencionados da trajetória econômica e espacial da RMC, bem cabem as considerações abaixo:

A existência de cada cidade tem uma lógica e uma fundamentação histórico-cultural própria que, a despeito de inexoravelmente articulada com as demais, seja internamente no nível específico de análise considerado - local, regional, nacional - seja no nível global, subsistem sob a forma de seu patrimônio (cultural, físico-natural, social, econômico e político), subvertendo tentativas hegemônicas da imposição de um roteiro de qualidade universal. É neste esforço que se situam os desafios para novas leituras dos movimentos de reestruturação das metrópoles.
...Uma sustentabilidade que não é só do ambiente e dos recursos físico-naturais, mas também e principalmente do tecido social, das vertentes políticas e das construções culturais. (GOMES, 2002, p. 136-137)

À luz dessas considerações sobre o setor serviços em Curitiba, nota-se que as informações sobre número de empresas e postos de trabalho acabam evidenciando a centralidade de Curitiba na formação espacial do aglomerado metropolitano e sugerem a caracterização desse aglomerado como espaço crescentemente internacionalizado, embora a análise qualitativa dos tipos de atividades no setor serviços seja mais adequada para a análise dessa última questão. Vejamos as séries mais recentes, com especial atenção para as cidades que compõem a área conurbada, conforme as tabelas 4 e 5 .

O que pode ser verificado é que os maiores desempenhos coincidem com o das cidades que se encontram com sua área conurbada com Curitiba.

Agora, passando à análise das condições qualitativas da inserção de Curitiba nas redes globais pela linha da comercialização internacional, com base em dados do Ministério das Relações Exteriores, nota-se que Curitiba tem a conceituação B1, segundo a agência internacional de classificação de risco. ${ }^{16}$ Isso quer dizer que a cidade oferece mais segurança para o pagamento de suas dívidas em moedas estrangeiras, resultando em maior facilidade para obter e negociar condições de financiamento para investimentos de longo prazo. Assim, Curitiba passa a ter condições de obter taxas de juros mais baixas na captação de recursos externos para as empresas estabelecidas em sua região, ficando a apenas quatro degraus do grau de confiança máxima dos mercados (PREFEITURA MUNICIPAL DE CURITIBA, 2004).

Em decorrência dos principais investimentos anunciados por cidade e empresa entre o período de 1995 e 2000, como é demonstrado por Macedo, Vieira e Meiners (2005, p. 14-19), a RMC passou a ser um dos mais importantes pólos da indústria automobilística brasileira e do Mercosul. Pelo alto grau de internacio-nalização das empresas dessa indústria, somado à expansão das atividades de serviços propiciada pelas demandas dessas novas empresas, o município de Curitiba se firmou como "um dos elos da rede de núcleos dinâmicos - cada

${ }^{16}$ A avaliação da Moody's serve de balizador para bancos e instituições financeiras estrangeiras, apontando as cidades, estados, países e empresas que oferecem melhores condições de pagamento de suas dívidas. Outras avaliações de risco econômico podem ser realizadas observando-se alguns parâmetros consagrados e aceitos pelo mercado internacional, como por exemplo o rating do Comitê de Risco da Austing Rating, que avalia o desempenho de empresas e/ou bancos, sendo um conceito A a tradução para o significado de baixo risco de crédito (AUSTING RATING, 2004). 
TABELA 4 - ATIVIDADES ECONÔMICAS - ESTABELECIMENTOS NOS MUNICÍPIOS DA RMC 2000 A 2003

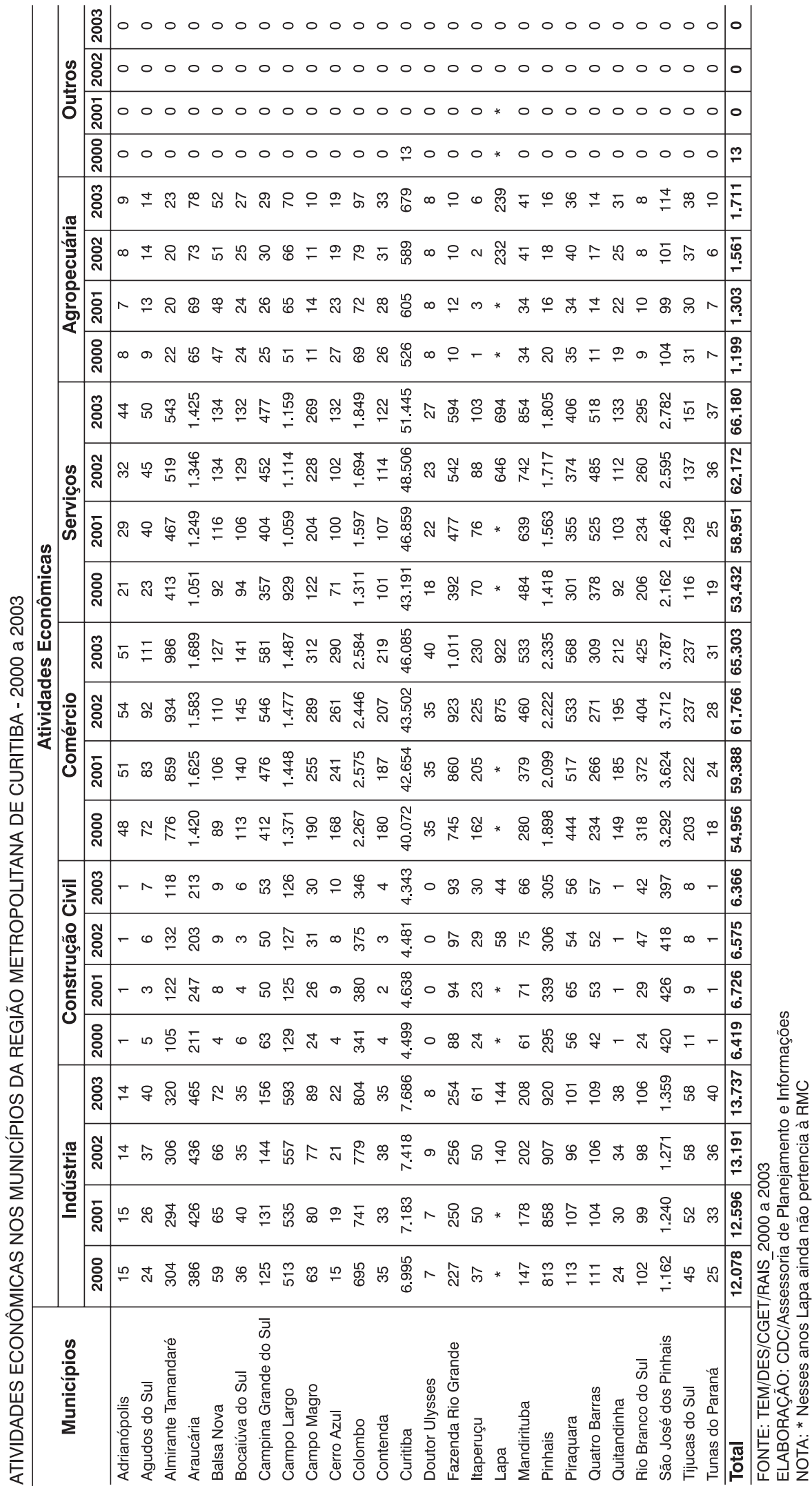


TABELA 5 - EMPREGOS NOS MUNICÍPIOS DA RMC - 2000 A 2003

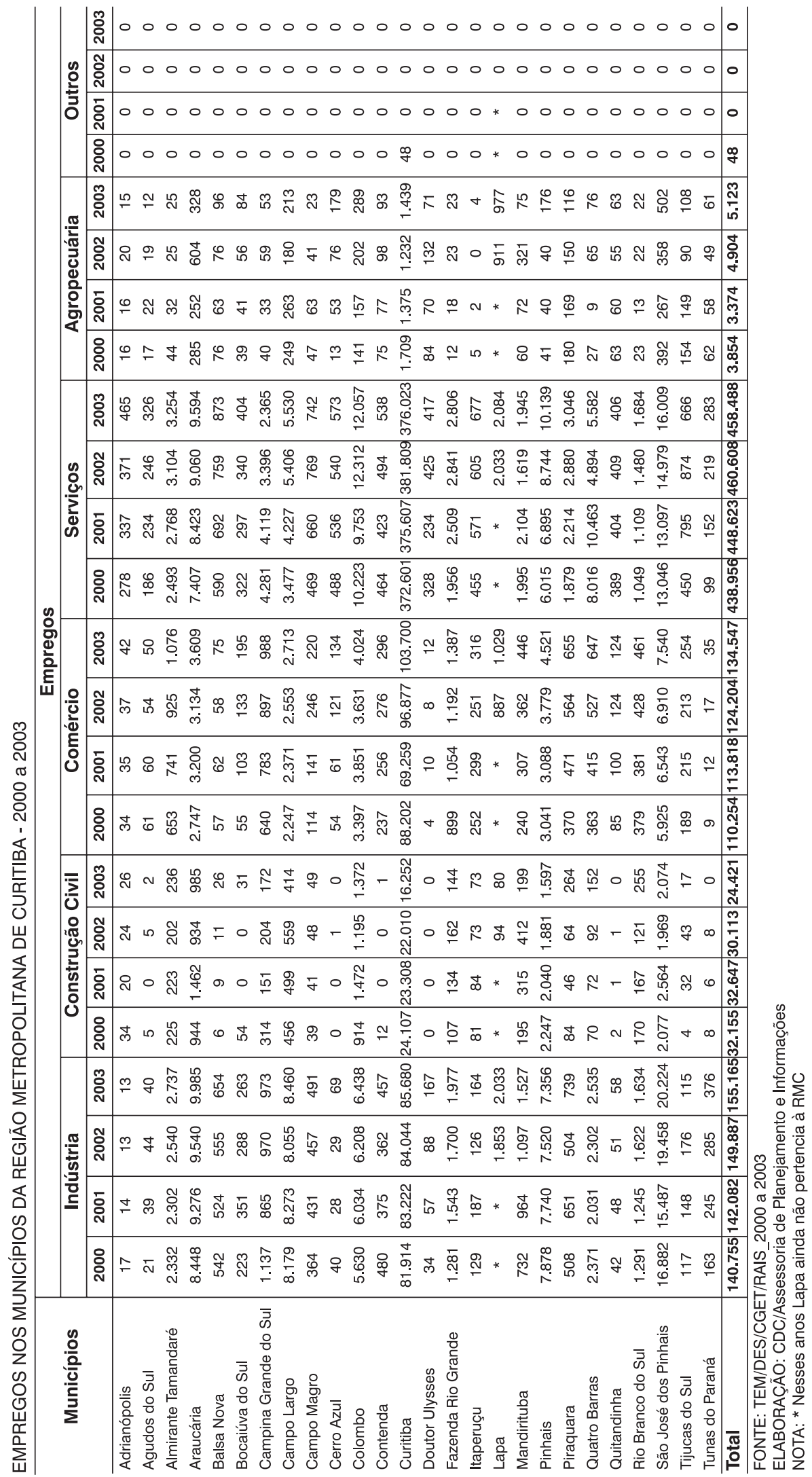


vez mais integrada e articulada com o exterior - a qual está passando a definir o processo de criação de riquezas na economia brasileira".

Essas transformações em curso na RMC são apontadas como sendo de tal intensidade que corresponderiam ao processo de constituição de uma "cidade-região global", isto é, um dos nós espaciais essenciais da economia global e também um dos atores políticos específicos na cena mundial, conforme a definição apresentada por Scott (2001, p. 11-25).

O volume de investimento externo direto - IED oriundo do Protocolo de Intenções de Investimento no Estado do Paraná para 1996 a 2000 sugere esse processo: de 209 intenções de investimentos assinadas, 51 estavam direcionados para a indústria automobilística na RMC; do total de investimentos realizados, 101 ocorreram em 11 municípios que fazem parte do aglomerado metropolitano de Curitiba, representando $48,3 \%$ dos investimentos no estado do Paraná, num volume de $\mathrm{R} \$$ $5.776,6$ milhões. Os outros 388 municípios do estado receberam 108 investimentos, correspondentes a $R \$$ 4.220,7 milhões. Das cidades da região de Curitiba, as que receberam maior volume de investimento, em ordem decrescente, foram: São José dos Pinhais, Araucária, Campo Largo, Curitiba, Fazenda Rio Grande, Quatro Barras, Campina Grande do Sul, Piraquara, Almirante Tamandaré, Pinhais e Colombo (BITTENCOURT, 2003, p. 108).

Tais informações reforçam a tese de que a inserção de Curitiba nas redes urbanas e globais deve ser feita tomando por base um espaço mais amplo que o da cidade núcleo: "todo o aglomerado metropolitano é Curitiba, não são lógicas parciais que se somam, mas uma lógica única que perpassa todos os municípios do aglomerado, [...] unidade que se constrói com contradições e correlações", redefinindo a "lógica de localização de atividades e pessoas" (FIRKOWSKI, 2001, p. 141).

Com esse incremento de investimentos, bastante sensível na indústria automobilística, observa-se um impacto sobre as atividades de serviço de alta qualidade, voltadas para o setor produtivo. Como observa Bittencourt
(2003, p. 118), "Curitiba deixa de abrigar grandes investimentos industriais, que se espraiam pela cidade-região, e transforma-se numa prestadora de serviços especializados para a indústria em ascensão fora de seus limites".

Isso reforça a posição de Curitiba no conjunto das cidades brasileiras mais bem equipadas e em condições de dar continuidade ao processo de expansão de atividades econômicas modernas. Assim, acompanhando o processo de expansão populacional, aumenta o número de shopping centers (11 unidades em 1995 e 21 em 2003), assim como o de hipermercados (3 unidades em 1995 e 15 em 2003, com destaque para as novas unidades de grandes empresas transnacionais, quais sejam, Sonae, Wall Mart e Carrefour). A rede de hotéis e flats internacionais também se amplia, acompanhando o aumento do turismo de negócios propiciado pela presença de grandes grupos transnacionais dos setores industrial e de serviços. O que se observa com toda essa movimentação é que parte da renda gerada nos municípios do aglomerado que passaram por essa reestruturação produtiva urbano-industrial é direcionada aos principais centros de consumo de Curitiba.

Adicionalmente, o aumento da produção industrial realizada por empresas transnacionais, em boa parte, visando o mercado externo, reflete-se nas atividades de comércio exterior, ou seja, na exportação e importação de produtos e também de serviços, o que demanda uma análise sobre o desempenho da região no comércio internacional. ${ }^{17}$ Nesse sentido, cabe examinar os dados relativos ao volume de negócios de importação e exportação, inclusas as atividades de serviços concomitante com a comercialização de produtos, sendo possível verificar um crescimento em termos de internacionalização.

Abaixo, também em resultados gerais, de período mais recente, uma apresentação dos totais brasileiros, os dados e volumes relativos a São Paulo (classificada como cidade global por pesquisas brasileiras) e os dados e volumes relativos a Curitiba por porte de empresa. Como pode ser observado, os valores e quantidades respectivos a Curitiba revelam um grande distanciamento

${ }^{17}$ Como não existe uma circulação de serviços, o conceito de exportação deve ser definido a partir das repercussões internacionais inerentes a uma determinada prestação. Deste modo e, considerando os diversos elementos que compõem uma prestação de serviços, pode haver diversas maneiras para se estabelecer a sua conexão com o exterior, a fim de qualificá-la como uma exportação. Com efeito, o serviço poderá ser considerado exportado em função do local: (i) da efetiva prestação; (ii) da residência ou do estabelecimento do tomador; (iii) do efetivo consumo ou resultado; e, finalmente, (iv) da procedência do pagamento. ... para ser considerada uma exportação, o serviço deve ser executado integralmente no exterior ou, ainda que seja desenvolvido no país, seus resultados devem ser produzidos no exterior. ... o pressuposto lógico para caracterizar uma exportação é que o serviço advenha do Brasil, isto é, que o prestador esteja localizado em território nacional. Assim, os elementos de conexão eleitos pela LC n. 116 serão aptos a designar se o serviço prestado por contribuinte brasileiro está sujeito às regras gerais de tributação interna ou às normas de desoneração pertinente às exportações. A LC n. 116 define exportação de serviços a partir do local da efetiva prestação e, especialmente, o local do consumo ou resultado do serviço. ... (FRANCO FILHO, 2004) 
DINIZ FILHO, L.L.; CROOPE, S. A inserção do aglomerado...

TABELA 6 - EXPORTAÇÕES DE CURITIBA, 1992-1996

\begin{tabular}{|c|c|}
\hline ANO & CURITIBA (valores em US\$ milhões FOB) \\
\hline 1992 & 454 \\
\hline 1993 & 558 \\
\hline 1994 & 685 \\
\hline 1995 & 724 \\
\hline 1996 & 863 \\
\hline
\end{tabular}

FONTE: MICT/SECEX, SICT/ICPI - BOLETIM CURITIBA INFORMAÇÕES SÓCIO-ECONÔMICAS, 1997.

TABELA 7 - EXPORTAÇÕES BRASILEIRAS - PORTE DE EMPRESA, SÃO PAULO/CURITIBA, 2002-2003

\begin{tabular}{|c|c|c|c|c|c|c|c|c|c|c|c|c|}
\hline \multirow{3}{*}{ Municípios } & \multicolumn{4}{|c|}{2003} & \multicolumn{4}{|c|}{2002} & \multicolumn{4}{|c|}{ Variação } \\
\hline & \multicolumn{2}{|c|}{$\mathrm{N}^{\circ}$ empresas } & \multicolumn{2}{|c|}{ US\$ FOB } & \multicolumn{2}{|c|}{$\mathrm{N}^{\circ}$ empresas } & \multicolumn{2}{|c|}{ US\$ FOB } & \multicolumn{2}{|c|}{$\mathrm{N}^{\circ}$ empresas } & \multicolumn{2}{|c|}{ US\$ FOB } \\
\hline & Quantid & $\%$ & Valor & $\%$ & Quantid & $\%$ & Valor & $\%$ & ABS & REL & ABS & REL \\
\hline Total geral & 19.796 & 100,00 & 73.084 .139 .518 & 100,00 & 19.340 & 100,00 & 60.361 .785 .544 & 100,00 & 455 & 2,36 & 12.722 .353 .974 & 21,08 \\
\hline $\begin{array}{l}\text { Micro } \\
\text { empresas }\end{array}$ & 4.578 & 23,13 & 220.351 .386 & 0,30 & 4.301 & 22,24 & 168.004 .825 & 0,28 & 277 & 6,44 & 52.346 .561 & 31,16 \\
\hline São Paulo & 761 & 3,84 & 29.629 .349 & 0,04 & 786 & 4,06 & 27.139 .348 & 0,04 & -25 & $-3,18$ & 2.490 .001 & 9,17 \\
\hline Curitiba & 120 & 0,61 & 5.462 .156 & 0,01 & 93 & 0,48 & 3.091 .476 & 0,01 & 27 & 29,03 & 2.370 .680 & 76,68 \\
\hline $\begin{array}{l}\text { Pequenas } \\
\text { empresas }\end{array}$ & 4.901 & 24,76 & 1.515 .654 .545 & 2,07 & 4.836 & 25,01 & 1.165 .762 .630 & 1,93 & 65 & 1,34 & 349.891 .915 & 30,01 \\
\hline São Paulo & 727 & 3,67 & 139.725 .405 & 0,19 & 762 & 3,94 & 126.569 .674 & 0,21 & -35 & $-4,59$ & 13.155 .731 & 10,39 \\
\hline Curitiba & 93 & 0,47 & 30.896 .494 & 0,04 & 91 & 0,47 & 21.167 .073 & 0,04 & 2 & 2,20 & 9.729 .421 & 45,96 \\
\hline $\begin{array}{l}\text { Médias } \\
\text { empresas }\end{array}$ & 5.649 & 28,54 & 5.844 .372 .973 & 8,00 & 5.695 & 29,45 & 4.655.163.152 & 7,71 & -46 & $-0,81$ & 1.189.209.821 & 25,55 \\
\hline São Paulo & 803 & 4,06 & 361.968 .612 & 0,50 & 884 & 4,57 & 314.609 .098 & 0,52 & -81 & $-9,16$ & 47.359 .514 & 15,05 \\
\hline Curitiba & 87 & 0,44 & 105.187.787 & 0,14 & 90 & 0,47 & 92.334 .219 & 0,15 & -3 & $-3,33$ & 12.853 .568 & 13,92 \\
\hline $\begin{array}{l}\text { Grandes } \\
\text { empresas }\end{array}$ & 4.208 & 21,26 & 65.400 .550 .940 & 89,49 & 4.140 & 21,41 & 54.313.991.357 & 89,98 & 67 & 1,64 & 11.086 .559 .583 & 20,41 \\
\hline São Paulo & 440 & 2,22 & 4.258 .658 .403 & 5,83 & 450 & 2,33 & 3.603 .847 .592 & 5,97 & -10 & $-2,22$ & 654.810 .811 & 18,17 \\
\hline Curitiba & & & & & & & & & & & & \\
\hline
\end{tabular}

FONTE: MINISTÉRIO DO DESENVOLVIMENTO, INDÚSTRIA E COMÉRCIO EXTERIOR - 2005. ${ }^{18}$

dos de São Paulo, o que, por extrapolação, reflete a dinâmica socioeconômica financeira das cidades.

Portanto, fica evidente que, apesar da inserção crescente nas redes globais, Curitiba ainda tem um bom caminho a percorrer, pois está numa classificação hierárquica abaixo da cidade brasileira mais próxima classificada como cidade global - São Paulo. A verificação do volume de exportações e importações, bem como da qualidade dos produtos e serviços, permite uma avaliação quanto ao estágio de desenvolvimento de Curitiba, tomando por base os critérios usados pelo IBGE para hierarquizar a rede urbana brasileira, classificando suas principais cidades e metrópoles.
Curitiba é identificada, dentro da classificação de metrópoles globais, nacionais e regionais proposta em Motta (IPEA, 2000, p. 37), se enquadrando dentro de uma das categorias espaciais dentro da rede urbana brasileira, aglomerações urbanas desenvolvidas a partir de um núcleo constituído pela capital do estado, com ocorrência de complementaridade funcional entre o centro e a periferia. O centro exercendo funções polarizadoras, de articulação espacial da aglomeração com algum grau de contigüidade, ao longo de eixos viários, e elevado grau de concentração.

São Paulo e Rio de Janeiro, identificadas nessa pesquisa como metrópoles globais, abrangem $17,3 \%$ da

${ }_{18}$ Observou-se na tabela do ministério, donde foram retirados esses dados, que não consta destaque para Curitiba para o item grandes empresas, mas há destaque para Paranaguá (22 empresas) e São José dos Pinhais (28 empresas). 
população total do país, enquanto Curitiba, que é classificada como uma metrópole nacional/ ${ }^{19}$ (mesmo grupo de Porto Alegre), concentrando aproximadamente $6 \%$ do total da população brasileira em 25 municípios. Dessa maneira, podemos verificar que Curitiba faz parte do sistema urbano regional Centro-Sul, formado por grandes estruturas articuladas e diferenciadas presentes no processo de urbanização nacional (MOTTA - IPEA, 2000). ${ }^{20}$

Segundo os estudos apresentados no documento da Emplasa (2004, p. 20-28), um dos efeitos da globalização da economia é o de fazer com que as cidades mundiais atuem como "replicadores e amplificadores de novas dinâmicas sociais, políticas, culturais e tecnológicas". Curitiba apresenta este tipo de comportamento. Além disso, "as redes das cidades são baseadas nos fluxos de diversas naturezas que trocam entre si (pessoas, mercadorias, capital, informação, energia, etc)", circulando através de canais como vias de transporte aéreo, aquático, terrestre, cabos, dutos ou irradiação de ondas eletromagnéticas.

Mais adiante nesse documento (p. 29), Curitiba é classificada como centro de terceiro nível da rede urbana nacional (aquele caracterizado pelas funções de cooperação), juntamente com cidades como Brasília, Salvador, Belo Horizonte, Porto Alegre, Fortaleza, Vitória, Manaus, Goiânia, Triângulo Mineiro, vale do Itajaí e Belém. ${ }^{21}$ Vale dizer, como cidade cujas funções são diferentes dos níveis de competição e parceira (primeiro e segundo níveis, respectivamente).

Ainda segundo essa mesma pesquisa, o município de Curitiba ocupa o $7^{\circ}$ lugar nacional em termos de população ${ }^{22} \mathrm{e}$, somado à sua região metropolitana, representam uma concentração populacional de $6 \%$ do total brasileiro das regiões metropolitanas, enquanto a região metropolitana de São Paulo concentra $48 \%$ de população ( $p$.
31). O município de Curitiba contava com 63.287 empresas em 1996, o que a colocava em $5^{\circ}$ lugar no ranking entre as cidades brasileiras - (São Paulo contava com 371.569 empresas) ${ }^{23}$-, dado esse que funciona como uma proxy da intensidade do volume de negócios e dos fluxos de informações realizados na região, de maneira a indicar o grau de inserção da cidade junto às redes globais em comparação com outras grandes cidades do país.

Para além do setor serviços, é interessante observar que a expansão industrial recente de Curitiba, mercê da conformação de novos complexos de produção flexíveis, localizados às margens de importantes rodovias e com facilidade de acesso ao Porto de Paranaguá e ao Aeroporto Internacional Afonso Pena, trouxe consigo um aumento importante no volume de cargas transportadas, sobretudo no período de 1995 em diante, marcado pela instalação/operação das novas indústrias, como observa Firkowski (2005). Essas estatísticas são produtos da importância assumida pelo transporte de componentes e pela exportação de produtos finais, conforme pode ser percebido na tabela a seguir.

Com efeito, Firkowski (2005, p. 20) explica que essa nova lógica produtiva e de localização de indústrias modernas na RMC tem servido para reforçar a base local de serviços, para o atendimento tanto das demandas das empresas quanto das demandas de consumo da parcela da população a elas associadas, como é o caso dos "serviços especializados para empresas - publicidade e propaganda, administração e gerenciamento de redes corporativas, logística e manutenção - e dos equipamentos comerciais e de serviços, tais como bancos, centros de negócios, espaços para eventos e feiras, rede hoteleira, hipermercado e shopping centers".

Um patamar mínimo de qualidade de vida urbana é requerido para a organização social e para favorecer os

${ }^{19}$ A metrópole nacional caracteriza-se por uma mancha de ocupação derivada de conurbação e/ou periferização, diretamente polarizada pela metrópole, envolvendo municípios limítrofes com contigüidade, continuidade e/ou descontinuidade de ocupação. Apresentam população urbana e densidade demográficas elevadas, forte articulação econômica, intensos fluxos de relações intermunicipais com comutação diária, complementaridade funcional e população ocupada em atividades urbanas (setores secundário e terciário). Municípios contíguos são os vizinhos com alta densidade e mancha de ocupação única; contínuos são os municípios vizinhos com alta densidade e mancha de ocupação independente, porém com tendência a tornar-se única e; descontínuos, os municípios próximos, com forte articulação econômica e social (MOTTA - IPEA, 2000, p. 68).

${ }^{20}$ Os sistemas urbanos regionais brasileiros são: "Belo Horizonte (área de influência de Belo Horizonte), Rio de Janeiro (Rio de Janeiro, Juiz de Fora e Vitória), São Paulo (São Paulo, Campinas, Bauru, Ribeirão Preto, Marília, São José do Rio Preto, Presidente Prudente e Uberlândia), Curitiba (Curitiba, Londrina, Maringá e Florianópolis), e Porto Alegre (Porto Alegre, Santa Maria, Pelotas e Passo Fundo)".

${ }^{21}$ No estudo da Emplasa, a cidade do Rio de Janeiro está incluída no terceiro nível da rede nacional, ao passo que, no estudo do IPEA, conforme já indicado, o Rio de Janeiro seria, assim como São Paulo, componente da rede global de cidades. Mas, como essa cidade não é o foco desta pesquisa, não será feita uma discussão a respeito dessa diferença entre as classificações.

${ }^{22}$ A ordem de concentração até Curitiba é, em ordem decrescente: São Paulo, Rio de Janeiro, Salvador, Belo Horizonte, Fortaleza, Brasília e daí Curitiba.

${ }^{23}$ Todos os dados citados neste parágrafo têm como ano base 1996, vários dos quais foram originalmente apresentados pelo IBGE, segundo o trabalho da Emplasa referencia. Após São Paulo, temos Rio de Janeiro com 131.118 empresas, Belo Horizonte com 73.470 empresas, Porto Alegre com 66.557 empresas, e então Curitiba. 
DINIZ FILHO, L.L.; CROOPE, S. A inserção do aglomerado...

TABELA 8 - MOVIMENTO NO AEROPORTO INTERNACIONAL AFONSO PENA - 1990/2003

\begin{tabular}{|c|c|c|c|}
\hline ANO & POUSOS E DECOLAGENS & $\begin{array}{c}\text { PASSAGEIROS (emb. }+ \\
\text { desemb.) }\end{array}$ & CARGA DESEMBARCADA (Kg) \\
\hline 1990 & 30.125 & 950.109 & 4.530 .174 \\
\hline 1995 & 36.646 & 1.272 .522 & 4.272 .955 \\
\hline 1998 & 62.610 & 2.040 .407 & 10.284 .997 \\
\hline 1999 & 47.325 & 1.514 .589 & 11.757 .549 \\
\hline 2002 & 67.672 & 2.760 .130 & 30.256 .011 \\
\hline 2003 & 54.298 & 2.512 .790 & 20.729 .587 \\
\hline
\end{tabular}

FONTES: INFRAERO E FIRKOWSKI (2005, p. 13)

indivíduos na obtenção de renda, qualidade essa determinada pelo acesso a bens e serviços urbanos, bem como pela apropriação do solo mediada pelo mercado. Assim, verifica-se a concentração de atividades mais complexas da base produtiva nas aglomerações urbanas e metropolitanas, que reflete as faixas mais altas de renda familiar per capita, porém com grandes diferenças internas. Ora, Curitiba possui faixas superiores em até cinco vezes às menores faixas ocorrentes em municípios da própria região. O pólo metropolitano de Curitiba tem uma proporção de $12,88 \%$ dos chefes de domicílio com rendimento até um salário mínimo, sendo que "os municípios do entorno imediato, com contigüidade de mancha de ocupação, elevam essa proporção para a ordem de $20 \%$; os do entorno mais distante, acima de 30\%" (IPEA, 2000, p. 76).

Nas metrópoles e centros maiores, o custo de vida (cesta básica, aluguéis, transportes, entre outros itens) é mais elevado que nas menores cidades. Nesse contexto, "a instrução é fundamental para que indivíduos e grupos sociais sejam ou não incluídos entre os que têm acesso aos benefícios e às vantagens que as cidades podem oferecer". Na região Sul, onde se encontra a metrópole de Curitiba, em 1991, cerca de $10 \%$ da população em idade ativa para o trabalho (mais de 15 anos) era analfabeta: fora do mercado formal de trabalho; mas corresponde as melhores posições no estado (IPEA, 2000 , p. 77$)^{24}$.

À luz das considerações realizadas, podemos concluir que Curitiba, apesar de distante da centralidade das principais cidades globais, como Nova lorque, ou mesmo da centralidade de São Paulo, apresenta um movimento em curso de integração às redes globais. Esse processo se materializa na industrialização operada sob a égide do novo paradigma tecnológico das empresas rede, na expansão e diversificação do setor serviços (inclusive com aumento das exportações desse setor), nos investimentos realizados por empresas transnacionais da indústria e do comércio e, por fim, na conseqüente diversificação do mercado de trabalho urbano, verificada inclusive em alguns segmentos do setor serviços que abrangem atividades importantes para a efetivação de transações econômicas globalizadas.

\section{CONSIDERAÇÕES FINAIS}

Como visto inicialmente, o aglomerado metropolitano de Curitiba assumiu uma posição de destaque dentro do processo de modernização e desconcentração industrial brasileira dos anos recentes em virtude da combinação de políticas de "guerra fiscal" com a oferta de fatores de produção favoráveis às indústrias de bens de capital e de duráveis de consumo. Uma vez realizados esses investimentos industriais, as vantagens competitivas iniciais da região são reforçadas, na medida em que as novas plantas atraem trabalhadores qualificados de outras regiões e dos países sedes das empresas multinacionais, bem como investimentos nos serviços e no comércio.

De fato, a análise dos inúmeros fatores que atuam sobre o mercado de trabalho local permite verificar que, dos anos 90 em diante, houve um significativo aumento da participação do aglomerado metropolitano na economia globalizada. Embora os dados disponíveis não permitam avaliar esse processo de forma precisa, pois sistematizados para atender a outras finalidades administrativas e/ou analíticas, não há dúvida de que houve uma

\footnotetext{
${ }^{24}$ Curitiba tinha menos de $10 \%$ de analfabetos nesta época, com uma média aproximada de 6,4 anos de estudo. Se comparada com uma das cidades do entorno metropolitano, como Rio Branco do Sul, cujo tempo médio de estudo é de 3,5 anos, confirmamos a diferença entre o núcleo e as cidades em volta, na metrópole.
} 
mudança importante da posição ocupada pelo aglomerado de Curitiba nas redes globais. Essa região vem buscando tornar-se um lugar inteligente, onde é possível identificar empresas transnacionais e espaços internacionalizados. A ação do planejamento, embora em grande parte baseada em políticas bastante questionáveis de "guerra fiscal" (DINIZ FILHO, 1998), buscou trazer uma nova dimensão urbano-industrial para a região, provocando efeitos diversos sobre as condições locais do mercado, manifestas na diversificação das atividades econômicas e no surgimento de novos postos de trabalho, num processo de reestruturação produtiva e socioespacial que acompanha os modelos internacionais.

Assim, a atração de investimentos em indústrias modernas, o crescimento demográfico, com diversificação dos estratos de renda, a conurbação e o surgimento de um novo padrão de periferização urbana, em que se combinam a tradicional formação de bairros populares com condomínios residenciais de alto padrão, a intensificação dos fluxos de informação e de capital, são ele- mentos que servem como base comparativa para averiguar o reposicionamento de Curitiba nas redes globais. Realmente, a verificação dessas mudanças, sem qualquer consideração de caráter quantitativo ou análises comparativas poderia levar a uma caracterização apressada de Curitiba como uma "cidade-região global", quando a comparação com região metropolitana de São Paulo aponta, na verdade, um grande distanciamento.

Nesse sentido, com base nas informações quantitativas e qualitativas apresentadas, verifica-se que Curitiba está num processo de inserção nas redes globais, participa do processo de globalização, sofre e contribui para mudanças socioeconômicas que extrapolam a escala local, sobretudo no que diz respeito ao seu mercado de trabalho, mas não chega a constituir uma cidade global. Dependendo da continuidade ou não dos processos encetados nos anos 90, bem como da intensidade dos mesmos, é possível que Curitiba venha a alcançar esse status nas próximas décadas. Não há, contudo, determinações objetivas que permitam antecipar esse resultado.

\section{REFERÊNCIAS}

BITTENCOURT, Jackson Teixeira. Perfil produtivo e dinâmica espacial da Região Metropolitana de Curitiba: uma leitura a partir do desenvolvimento regional e das mudanças no padrão de produção. Revista Paranaense de Desenvolvimento, Curitiba, n. 105, jul./dez., 2003.

CDC. Evolução dos estabelecimentos de serviços em Curitiba - 1996-2002 - Companhia de Desenvolvimento da Curitiba Metrópole. CDC: 2004.

CIC. Mercado de Trabalho em Curitiba e Região Metropolitana (versão preliminar) - CIC - Curitiba - PR, set. 2001. Documento fotocopiado.

COMEC. Metrópolis em Revista, Planejamento Regional Região Metropolitana de Curitiba, Coordenação da Região Metropolitana de Curitiba. - v. 4, n. 1. Curitiba: Comec Brasil, 2002.

Plano de Desenvolvimento Integrado da Região Metropolitana de Curitiba - Documento Síntese para Discussão. Coordenação da Região Metropolitana de Curitiba - Secretaria de Estado do Planejamento e Coordenação Geral SEPL - Governo do Estado do Paraná. Curitiba: Comec Brasil, 2001.

CROOPE, Silvana. Impacto do processo de inserção do aglomerado metropolitano de Curitiba nas redes globais sobre o mercado de trabalho local a partir dos anos 90. Curitiba, 2001. Dissertação (Mestrado em Geografia) - Departamento de Geografia, Universidade Federal do Paraná.

CURITIBA. Boletim: Curitiba informações sócio-econômicas - Região Metropolitana de Curitiba. Prefeitura Municipal de
Curitiba, Secretaria Municipal da Indústria, Comércio e Turismo, 1997.

DIAS, Leila C. A cidade, a metrópole e o modo de vida: notas para discussão. In: CARLOS, Ana Fani Alessandri; LEMOS, Amália Inês Geraiges. (Orgs.). Dilemas urbanos: novas abordagens sobre a cidade. São Paulo: Contexto, 2003.

DINIZ FILHO, Luis Lopes. A dinâmica regional recente no Brasil: desconcentração seletiva com "internacionalização" da economia nacional. São Paulo, 2000. Tese (Doutorado em Geografia) - Departamento de Geografia, FFLCH - Universidade de São Paulo.

Desigualdades regionais e conflitos federativos no Brasil: a guerra fiscal entre estados no contexto da integração competitiva. RA'E GA: o espaço geográfico em análise, v. 2, n. 2, p. 125-140, 1998.

EMPLASA, 25 anos. O complexo metropolitano expandido de São Paulo - Rede Urbana Nacional e Internacional. Disponível em: <http://barreiros.arq.br/textos/ cidades mundiais.PDF> Acesso em: 23 dez. 2004.

FIRKOWSKI, Olga Lúcia Castreghini de Freitas. A nova territorialidade da indústria e o aglomerado Metropolitano de Curitiba. São Paulo, 2001. 278 f. Tese (Doutorado em Geografia) - Departamento de Geografia da Faculdade de Filosofia, Letras e Ciências Humanas, Universidade de São Paulo.

A nova lógica de localização industrial no aglomerado Metropolitano de Curitiba. Revista Paranaense de Desenvolvimento, n. 103, jul./dez. 2002. IPARDES. Disponível em: <http://www.pr.gov.br/ipardes/ > Acesso em: 02 fev. 2005. 
FRANCO FILHO, Luiz Carlos Junqueira. Campo de Incidência do ISS em face da Lei Complementar n. 116/2003 - Importação e Exportação de Serviços - 18.5.2004. Comentários. Mariz de Oliveira, Siqueira Campos e Bianco Advogados S. C. Disponível em <http://www.marizsiqueira.com.br/ comunicados64.htm> Acesso em: 14 dez. 2004.

GOMES, Edvânia Tôrres Aguiar. Dilemas nas (re)estruturações das metrópoles. In: SPOSITO, Eliseu Savério (Ed.). Mudanças Globais - Terra Livre, ano 18, v. 1, n. 18. Publicação AGB jan./jun. 2002.

IBGE. Pesquisa Mensal do Emprego - Série Relatórios Metodológicos, Departamento de Emprego e Renda, Rio de Janeiro, v. 23, 2002.

IBGE. Revista Brasileira de Geografia, Rio de Janeiro, v. 57, n. 2, 1995.

INFRAERO. Movimento no aeroporto internacional Afonso Pena - 2002/2003. Disponível em: <http://www.infraero.gov.br/ aero prev movi.php?ai=64> Acesso em: 18 fev. 2005.

IPARDES. Instituto Paranaense de Desenvolvimento Econômico e Social. NOJIMA, Daniel; MOURA, Rosa; SILVA, Sandra Terezinha da (Orgs.). O setor serviço no Paraná Ano 2000. Versão Preliminar. Curitiba, 2004.

IPARDES. Dinâmica recente da economia e transformações na configuração espacial da Região Metropolitana de Curitiba. Núcleo de Estudos da Base Produtiva e do Desenvolvimento Regional. Primeira Versão. v. 3. Curitiba, dez. 2004. Disponível em: <http://www.pr.gov.br/ipardes/pdf/ primeira versao/Dinamica RMC.pdf> Acesso em: $02 \mathrm{fev}$. 2005.

IPEA - Instituto de Pesquisa Econômica Aplicada. MELO, Hildete Pereira de.; ROCHA, Frederico; FERRAZ, Galeno; Di SABBATO, Alberto; DWECK, Ruth. O setor de serviços no Brasil: uma visão global - 1985/1995. Rio de Janeiro, 1998. Discussão n. 549.

LUNARDI, Maria Elizabeth. Parques tecnológicos estratégias de localização em Porto Alegre, Florianópolis e Curitiba. Curitiba: Ed. do Autor, 1997.

MACEDO, Mariano de Matos et al. Caracterização geral do mercado de trabalho da Região Metropolitana de Curitiba e de seus municípios circunvizinhos. Curitiba: UFPR, SICT, SERT e DIEESE, 2005.

; VIEIRA, Viviane Fiedler; MEINERS, Wilhelm Eduard Milward de Azevedo. Fases de Desenvolvimento Regional no Brasil e no Paraná: da emergência de um novo modelo de desenvolvimento na economia paranaense. Revista Paranaense de Desenvolvimento, Curitiba, n. 103, jul./dez. 2002.

MINISTÉRIO DO DESENVOLVIMENTO, INDÚSTRIA E COMÉRCIO EXTERIOR. Exportações brasileiras por porte de empresas - 2002/2003. Disponível em: < $\underline{\text { http:// }}$ www.desenvolvimento.gov.br/arquivo/secex/porteempresa/ rpe 415.doc> Acesso em: 19 fev. 2005.

MOTTA, Diana M. da (Org). Caracterização e tendências da rede urbana do Brasil: redes urbanas regionais: Sul. IPEA, IBGE, UNICAMP/IE/NESUR, IPARDES. 1. reimp., Brasília: IPEA, 2000.

MOURA, Rosa; DELGADO, Paulo; DESCHAMPS, Marley; CARDOSO, Nelson Ari. A realidade das áreas metropolitanas e seus desafios na Federação Brasileira: diagnóstico socioeconômico e da estrutura de gestão. Disponível em: <http://www.pr.gov.br/ipardes/pdf/RMs\%20do\%20Brasil.pdf> Acesso em: 02 fev. 2005.

PARANÁ. Boletim: Programa de apoio à micro e pequena empresa. Programa troca imposto por emprego - Decreto beneficia Micro e Pequena Empresa Paranaense com Isenção e Diminuição de ICMS. fev. 2003.

PARANÁ. Informativo. Evolução do mercado formal de trabalho no Brasil, Paraná e Região Metropolitana de Curitiba no primeiro quadrimestre de 2004. SETP. Curitiba, maio 2004.

PARANÁ. Taxas de crescimento. IPARDES. Disponível em: <http://www.pr.gov.br/ipardes/pdf/proj 1991 2020.pdf > Acesso em: 27 jun. 2003.

PARANÁ. Taxas de crescimento. Governo do Estado do Paraná. Disponível em: <http://www.paranacidade.org.br/ municipios/select municipios.php> Acesso em: 08 set. 2003.

PREFEITURA MUNICIPAL DE CURITIBA. Moody's melhora avaliação de risco de investimentos em Curitiba. Publicado em 13/09/2004. Disponível em: <http://www.curitiba.pr.gov.br/ Noticia.aspx?not=3422> Acesso em: 14 dez. 2004.

SASSEN, Saskia. As cidades na economia mundial. Tradução de: Carlos Eugênio Marcondes de Moura. São Paulo: Studio Nobel, 1998. Coleção Megalópolis.

SCOTT, Allen J. et al. Cidades-regiões globais. Espaço \& Debates, São Paulo: Núcleo de Estudos Regionais e Urbanos, v. 17, n. 41, 2001.

UNIVERSIDADE FEDERAL DO PARANÁ. Biblioteca Central. Normas para apresentação de documentos científicos. 2: Teses, dissertações, monografias e trabalhos acadêmicos. Curitiba: Editora da UFPR, 2002.

Biblioteca Central. Normas para apresentação de documentos científicos. 6: Referências. Curitiba: Editora da UFPR, 2002.

Biblioteca Central. Normas para apresentação de documentos científicos. 7: Citações e notas de rodapé. Curitiba: Editora da UFPR, 2002.

Biblioteca Central. Normas para apresentação de documentos científicos. 8: Redação, editoração. Curitiba: Editora da UFPR, 2000. 